\title{
A Case Report of Orf Disease in a Greek Island: Diagnostic Tests or Interventions Are Not Necessary
}

\author{
M. Lalountas ${ }^{1}{ }^{*}$, A. Kriari1 ${ }^{1}$ C. Asteriou ${ }^{2}$, I. Tornikidis ${ }^{1}$, P. Lazaridis ${ }^{1}$ \\ ${ }^{1}$ Surgical Department, General Hospital, Health Centre of Lemnos, Lemnos, Greece \\ ${ }^{2}$ Department of Cardiothoracic Surgery, AHEPA University Hospital, Thessaloniki, Greece \\ Email: ${ }^{\text {miltiadislalountas@yahoo.gr }}$
}

Received 15 April 2014; revised 9 May 2014; accepted 12 May 2014

Copyright (C) 2014 by authors and Scientific Research Publishing Inc.

This work is licensed under the Creative Commons Attribution International License (CC BY). http://creativecommons.org/licenses/by/4.0/

c) (i) Open Access

\section{Abstract}

The Orf disease, also known as contagious ecthyma, is a zoonotic infection caused by a dermatotropic parapoxvirus that commonly infects small ruminants such as sheep and goats. It is transmitted to humans through contact with an infected animal or fomites. Human infection typically is associated with occupational animal contact. We recently treated a healthy 41-year-old woman who presented a hangnail lesion on the middle finger of her right hand. The lesion was hard cauliflower-like mass, granulomatous and painful. Surgical debridement and biopsy were performed for further investigation. The Orf disease is usually self-limiting and resolves in 6 - 10 weeks, but complications may occur. The diagnosis may be confirmed by electron microscopy, conventional histopathology or by isolation of the virus by PCR. Early clinical recognition and knowledge of this benign viral condition are vital to avoid unnecessary surgical intervention.

\section{Keywords}

Orf Disease, Parapoxvirus, Contagious Ecthyma, Hand, Treatment

\section{Introduction}

The Orf disease, also known as contagious ecthyma, is a zoonotic infection caused by a dermatotropic DNA virus that belongs to the Parapoxvirus genus of the family Poxviridae that commonly infects small ruminants such as sheep and goats [1]. Orf presents in animals as a pustular dermatitis or a vesicular oral mucosal lesion, and in humans as a single lesion on the site of infection [2]. Orf is transmitted by direct contact inoculation [3]. Hu-

*Corresponding author.

How to cite this paper: Lalountas, M., et al. (2014) A Case Report of Orf Disease in a Greek Island: Diagnostic Tests or Interventions Are Not Necessary. Modern Research in Inflammation, 3, 67-69. http://dx.doi.org/10.4236/mri.2014.32008 
mans acquire the infection from contact with infected or recently vaccinated animals and/or fomites in conjunction with skin trauma [4]. Human infection typically is associated with occupational animal contact. At risk are children after visiting petting zoos and livestock fairs. It also may be observed after the feast of sacrifice in Muslim countries. However, human-to-human transmission has not been reported [1].

\section{Case Report}

In September 2012, a 41-year-old Caucasian woman in Lemnos-Greece presented with a rapidly growing hangnail lesion on the middle finger of her right hand. The lesion was developed during three days, examined and noted to be $3 \times 2 \times 1 \mathrm{~cm}$, hard cauliflower-like mass, granulomatous and painful. The lesion was drained, releasing a small amount of serosanguinous fluid, but no pus (Figure 1). Routine bacterial cultures were negative. Surgical debridement and biopsy were performed for further investigation. Histopathology indicated inflammation of granulation tissue and dermal infiltrate of mixed inflammatory cells. Both pathological study and patient's personal medical history, who had contact with ruminants, confirmed the diagnosis of Orf virus infection.

\section{Discussion}

Orf is an infection often unknown to practicians throughout the world [5]. The first definition of orf disease and a published case report was by Newson \& Cross in 1934 [6]. In ruminants, the disease is known as "scabby mouth", "sore mouth", or "contagious pustular dermatitis" [7]. Lesions are localized to the buccal mucosa, the nares, the skin of the muzzle, the teats and udders. In humans [8] orf usually manifests on the hands, but unusual locations have been described including the nose, scalp, axilla, buttocks, and genitals [3] after a 3 - 7 day incubation period [1]. Lesion development follows a predictable pattern in the course of 6 - 10 weeks [7], with slow progression through the following stages: 1) papule, 2) vesicle, 3) shallow annular ulcer, 4) scab, and finally 5) healed skin, with little or no scarring. Most parapoxvirus infections in humans, including orf, are self-limited, except in immunocompromised hosts [9]. Symptoms include vesicular or necrotic skin lesions, pain, pruritis, lymphangitis, axillary lymphadenitis, and rarely fever or malaise [10]. Potential complications include erythema multiform, deforming scars, and secondary bacterial infections [1].

Although the transmission characteristics of orf virus from ruminant to human have not been fully delineated, infections tend to occur in the spring and summer months; this is coincident with the principal lambing season. Young animals are more susceptible to orf virus infection and when ill with orf often require assistance with feeding (by bottle or tube), which leads to more frequent close contact with their infected oral cavity and muzzle. In addition, some cases are coincident with vaccination of the herd. Orf virus vaccine is a live, unattenuated

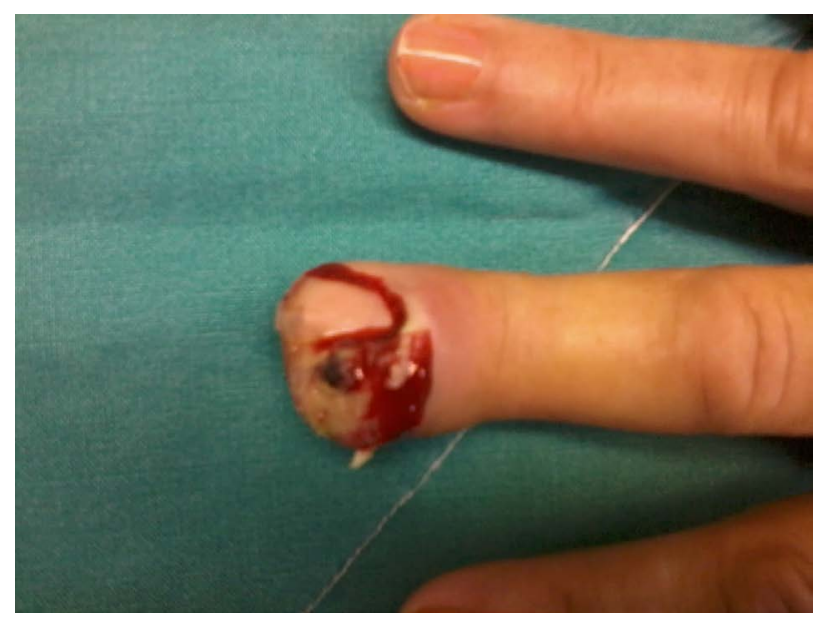

Figure 1. Orf disease (contagious ecthyma) on the middle finger of the right hand. A rapidly growing, hard cauliflower-like mass, granulomatous and painful lesion. The disease is an occupational, self-limiting, zoonotic infection without need of surgical debridement and antibiotic administration. 
vaccine that is administered to lambs postweaning in approximately 5\% of US sheep operations [9]. Therefore, barrier protection (e.g. nonporous gloves) and hand washing during the care of sheep and goats is recommended whenever feasible. These measures are especially important for any person with a compromised immune system or a chronic skin disorder (e.g. eczema) who has contact with overtly infected animals [4].

\section{Conclusion}

Although orf virus infection is self-limiting in hosts with normal immune systems, it can resemble skin lesions associated with potentially life-threatening zoonotic infections such as herpetic paronychial abscess, milker's nodules, cowpox, cutaneous anthrax, infection of Mycobacterium marinum, deep fungal infections, pyogenic granulomas, keratoacanthoma and malignant tumours [6]. A confirmatory parapoxvirus diagnosis can prevent unnecessary surgeries and inappropriate antibiotic administration, and evidence suggests that topical imiquimod treatment may hasten the resolution of parapoxvirus infections [7]. The diagnosis may be confirmed by electron microscopy, but is difficult in later stages of the disease, conventional histopathology or by isolation of the virus by PCR [11] [12]. Due to the typical clinical presentation and the self-limited natural course of the Orf disease, all of the above tests and interventions are often unnecessary and should be avoided if possible.

\section{References}

[1] Centers for Disease Control and Prevention (CDC) (2012) Human Orf Virus Infection from Household ExposuresUnited States, 2009-2011. MMWR Morbidity and Mortality Weekly Report, 61, 245-248.

[2] Mourtada, I., Le Tourneur, M., Chevrant-Breton, J. and Le Gall, F. (2000) Human Orf and Erythema Multiforme. Annals of Dermatology of Venereology, 127, 397-399.

[3] Frandsen, J., Enslow, M. and Bowen, A.R. (2011) Orfparapoxvirus Infection from a Cat Scratch. Dermatology Online Journal, 17, 9.

[4] Centers for Disease Control and Prevention (CDC) (2006) Orf Virus Infection in Humans-New York, Illinois, California, and Tennessee, 2004-2005. MMWR Morbidity and Mortality Weekly Report, 55, 65-68.

[5] Engel, H., Marot, L., Zech, F. and Thys, F. (2010) The “Orf” Virus: Focus and Review of the Literature. Revue Medicale de Liege, 65, 691-695.

[6] Uzel, M., Sasmaz, S., Bakaris, S., Cetinus, E., Bilgic, E., Karaoguz, A., Ozkul, A. and Arican, O. (2005) A Viral Infection of the Hand Commonly Seen after the Feast of Sacrifice: Human Orf (Orf of the Hand). Epidemiology \& Infection, 133, 653-657. http://dx.doi.org/10.1017/S0950268805003778

[7] Lederman, E.R., Green, G.M., DeGroot, H.E., Dahl, P., Goldman, E., Greer, P.W., Li, Y., Zhao, H., Paddock, C.D. and Damon, I.K. (2007) Progressive ORF Virus Infection in a Patient with Lymphoma: Successful Treatment Using Imiquimod. Clinical Infectious Diseases, 44, 100-103. http://dx.doi.org/10.1086/517509

[8] Taieb, A., Guillot, M., Carlotti, D. and Maleville, J. (1998) Orf and Pregnancy. International Journal of Dermatology, 27, 31-33. http://dx.doi.org/10.1111/j.1365-4362.1988.tb02331.x

[9] Erbağci, Z., Erbağci, I. and Almila Tuncel, A. (2005) Rapid Improvement of Human Orf (Ecthyma Contagiosum) with Topical Imiquimod Cream: Report of Four Complicated Cases. Journal of Dermatological Treatment, 16, 353-356. http://dx.doi.org/10.1080/09546630500375734

[10] Lederman, E.R., Austin, C., Trevino, I., Reynolds, M.G., Swanson, H., Cherry, B., Ragsdale, J., Dunn, J., Meidl, S., Zhao, H., Li, Y., Pue, H. and Damon, I.K. (2007) ORF Virus Infection in Children: Clinical Characteristics, Transmission, Diagnostic Methods, and Future Therapeutics. The Pediatric Infectious Disease Journal, 26, 740-744. http://dx.doi.org/10.1097/INF.0b013e31806211bf

[11] Khaled, A., Robbana, F., Hammami, H., Kharfi, M., El Fekih, N., Fazaa, B. and Kamoun, M.R. (2009) Orf of the Hand. Tunis Medicine, 87, 352-353.

[12] Hosamani, M., Scagliarini, A., Bhanuprakash, V., McInnes, C.J. and Singh, R.K. (2009) Orf: An Update on Current Research and Future Perspectives. Expert Review of Anti-Infective Therapy, 7, 879-893.

http://dx.doi.org/10.1586/eri.09.64 